\title{
Prescribing Pattern of Antibiotics Using WHO Prescribing Indicators Among Inpatients in Ethiopia: A Need for Antibiotic Stewardship Program
}

This article was published in the following Dove Press journal: Infection and Drug Resistance

\author{
Gebre Teklemariam Demoz (iD) \\ Gebremicheal Gebreslassie \\ Kasahun (iD) ' \\ Kalay Hagazy' \\ Gebremariam Woldu' \\ Shishay Wahdey ${ }^{2}$ \\ Degena Bahrey Tadesse (iD) ${ }^{3}$ \\ Yirga Legesse Niriayo (D) ${ }^{4}$ \\ 'School of Pharmacy, Aksum University, \\ Aksum, Ethiopia; ${ }^{2}$ School of Public \\ Health, Mekelle University, Mekelle, \\ Ethiopia; ${ }^{3}$ School of Nursing, Aksum \\ University, Aksum, Ethiopia; ${ }^{4}$ School of \\ Pharmacy, Mekelle University, Mekelle, \\ Ethiopia
}

Background: Irrational prescribing of antibiotics is a universal public health problem, leading to antibiotic resistance. Understanding the prescribing pattern of antibiotics is crucial to tackling irrational prescription. Yet, comprehensive studies regarding the prescribing pattern of antibiotics among inpatients and the need for an Antibiotic Stewardship Program (ASP) are lacking in Ethiopia. This study aimed to evaluate prescribing patterns of antibiotics and the need for an ASP.

Methods: A hospital-based prospective observational study was carried out from February 2019 to December 2019. This study was conducted among patients admitted to Aksum University Comprehensive Specialized Hospital, Ethiopia. Data were collected using a data abstraction format generated by World Health Organization (WHO) prescribing indicators. Data analysis was carried out using SPSS version 25.0.

Results: A total of 1653 antibiotics were prescribed for 822 inpatients. Overall, $52.3 \%$ of patients had at least one oral and/or injectable antibiotic prescribed, for a mean duration of $4.2(\mathrm{SD}=2.3)$ days. The average number of prescribed antibiotics per patient was 2.01 $(\mathrm{SD}=1.9)$. The majority $(97.6 \%)$ of antibiotics were prescribed by their generic name, and all prescribed antibiotics were from the national Essential Medicine List (EML). Frequently prescribed injectable and oral antibiotics were ceftriaxone $(24.5 \%)$ and azithromycin $(12.9 \%)$, respectively. Culture and sensitivity testing were not performed in any of the cases. During the study period, $65.2 \%$ of key antibiotics were available in stock.

Conclusion: In this study, more than half of patients were on at least one antibiotic, and all antibiotics were prescribed from the national EML. However, all antibiotics were prescribed empirically. This result shows that the prescribing pattern of antibiotics in the hospital deviates from and is non-compliant with the standard endorsed by WHO. This study provides evidence for the necessity and a way forward for the establishment of an ASP in the hospital that may help to introduce the prescribing of antibiotics with the aid of culture and sensitivity tests, and to develop institutional guidelines.

Keywords: WHO prescribing indicators, prescribing pattern, antibiotic stewardship program, Ethiopia

\section{Introduction}

Antibiotics are drugs used for treating infections caused by bacteria, and they have saved countless lives. ${ }^{1}$ Antibiotics are currently the most commonly prescribed drugs in hospitals worldwide. ${ }^{2,3}$ However, the inappropriate use of antibiotics contributes to the development of bacterial resistance, which accelerates the emergence and spread of resistant microorganisms and has a significant impact on the treatment outcome. ${ }^{1}$
Demoz

School of Pharmacy, College of Health

Sciences, Aksum University, Aksum,

Ethiopia

Tel +251914031986

Email gebretekl@gmail.com 
Antibiotic resistance (ABR) develops when potentially harmful bacteria change in a way that reduces or eliminates the effectiveness of the antibiotic. Although ABR is a common issue, the inappropriate use and malprescribing of antibiotics are increasing the incidence of $\mathrm{ABR} .{ }^{4} \mathrm{ABR}$ has been detected in all parts of the world; it is one of the greatest challenges to global public health today and the problem is growing. ${ }^{3}$ The increasingly rapid emergence and dissemination of ABR has become a worldwide problem during the past few decades. ${ }^{1,5,6}$

Currently, the Centers for Disease Control and Prevention (CDC) warns health professionals to work in improving antibiotic prescribing practice and use in human health care, and recommends the establishment of an Antibiotic Stewardship Program (ASP). ${ }^{7}$ Changing prescribing behaviors could be difficult, but there are proven, evidence-based methods to optimize antibiotic therapy for individuals while minimizing harm to the patient and reducing $\mathrm{ABR}$ in the community. Thus, the rational use of antibiotics is a major health need. ${ }^{2}$

Nowadays, more than ever before, ASP is of the utmost importance as a way to optimize the use of antibiotics to prevent the emergence of resistance and improve patient treatment outcomes. ${ }^{8}$ Thus, the use of the term "antibiotic stewardship" has grown exponentially in recent years, typically referring to programs and interventions that aim to optimize antibiotic use. ${ }^{8,9}$ ASP comprises interventions to prevent drug-resistant bacterial infections, select antibiotic therapy targeted toward susceptible or resistant bacteria, and reduce unnecessary or inappropriate antibiotic administration and use. ${ }^{10,11}$ In clinical practice, ASP focuses on coordinated interventions designed to improve and measure the appropriate use of antibiotic agents by promoting the timely selection of the optimal antibiotic regimen of dose, duration of therapy, and route of administration. ${ }^{12}$

There is no doubt that antibiotics have vital roles in healthcare systems worldwide and they are indispensable in all health-care settings. Although antibiotics are a cornerstone tool in health-care delivery in hospitals and save countless lives, up to half (20-50\%) of prescribed antibiotics are inappropriately consumed, worldwide. ${ }^{13}$ This has a substantial effect on the quality of the health-care system and therapeutic costs, and increases the rate of adverse drug events. ${ }^{2}$

Inappropriate use of antibiotics is prevalent, resulting in $\mathrm{ABR}$, which is a big challenge in society. ${ }^{1}$ Inappropriate use of these drugs could be harmful and lead to ABR. ${ }^{13,14}$ Patients with antibiotic-resistant infections are more likely to experience ineffective treatment, recurrent infection, delayed recovery, or even death. ${ }^{9,15}$ About $6.5 \%$ of morbidity and mortality of hospital admissions is related to inappropriate prescribing of antibiotics, although most of these events are preventable. ${ }^{16}$

ABR is dramatically accelerated when antibiotics are misused. This is serious, particularly in developing countries where antibiotics are not only misused but also often underused because of financial constraints. ${ }^{16,17}$ The study of prescribing patterns seeks to monitor, evaluate, and suggest modifications in practitioners' prescribing habits to make medical care more rational. ${ }^{4}$ In particular, inappropriate prescribing of antibiotics is commonly suspected in hospitalized patients, resulting in the spread of ABR. As a result, it needs special attention in order to combat the emergence and spread of ABR., ${ }^{2,7}$

Antibiotics are the most frequently prescribed drugs for hospitalized patients; for instance, a prospective study conducted in an Indian tertiary hospital showed that $95 \%$ of patients were on antibiotics at admission. ${ }^{18}$ Furthermore, in Pakistan, $82.3 \%$ of hospitalized patients were taking antibiotics, ${ }^{6}$ and a study conducted in Cameroon showed that antibiotics had been prescribed for $36.71 \%$ of participants. ${ }^{20}$ Poor infection control, lack of ASPs, and weak laboratory capacity for culture and sensitivity testing for antibiotics are the main factors in the occurrence of irrational antibiotic use. ${ }^{19}$ Studies have revealed that $20-50 \%$ of antibiotic utilization is not rational. ${ }^{13}$ Establishing ASPs in resource-limited settings may help to curb the rise of ARB. Understanding local resistance patterns and antibiotic usage may help to define appropriate empiric treatment regimens and gaps to facilitate ASP development. ${ }^{9}$

Many previous studies conducted among Ethiopian outpatients have reported high prescribing of antibiotics, such as $71.6 \%$ by Yallew et al, ${ }^{20} 74.7 \%$ by Woldu et al, ${ }^{21}$ $66.5 \%$ by Summoro et al, ${ }^{22} 58.1 \%$ by Desalegn, ${ }^{23} 56.0 \%$ by Worku and Tewahido, ${ }^{24} 49.6 \%$ Bilal et al, ${ }^{25}$ and $32 \%$ by Demeke et al. ${ }^{26}$ However, very limited data are available from Ethiopia, particularly in the study area, regarding the antibiotic prescribing patterns based on WHO antibiotic prescribing indicators among hospitalized patients, and the need for an ASP is uncertain.

Therefore, understanding the prescribing pattern of antibiotics is a key first step for the establishment of ASPs in such resource-limited settings. Thus, this study aimed to investigate prescribing patterns of antibiotics and identify the most frequently prescribed antibiotics for hospitalized patients. In addition, this work will add evidence for policymakers to design strategies and apply interventions to enhance 
the sensible prescribing of antibiotics among hospitalized patients in Ethiopia and more globally. Once the prescribing pattern of antibiotics has been determined, appropriate strategies can direct the ASP toward interventions that should be made to enhance the proper prescribing practice of antibiotics for hospitalized patients. It could also be helpful as an index for other researchers who are interested in this area.

\section{Methods}

\section{Study Setting}

The study was conducted at Aksum University Comprehensive Specialized Hospital (AKU-CSH). This hospital is the second largest tertiary health-care center in Tigray, Aksum, Ethiopia. The hospital is affiliated with Aksum University, College of Health Sciences. It is a teaching hospital for undergraduate and postgraduate medical and allied health sciences students. It is also the training center for those health professionals who are working in different health sectors of the region or country. The hospital is comprised of four main wards (pediatrics, medical, surgical, and gynecology/obstetrics). Among these, three wards (medical, surgical, and gynecology/obstetrics) were our study settings. Each ward in the hospital is staffed with respective specialists, general practitioners, nurses, and other health-care providers. However, there was no clinical pharmacy service for pharmaceutical care on any of the wards of the hospital.

\section{Study Design and Period}

A hospital-based prospective observational study design was used, from February 2019 to December 2019.

\section{Source and Study of Population}

All patients who were hospitalized in the selected wards of the hospital were the source of the population, and all patients admitted during the study period to the selected wards of the hospital who met the inclusion criteria were our study population.

\section{Eligibility Criteria}

All patients admitted to the study wards of the hospital during the study period were included. Patients on programmed antibiotics for long-term therapy (patients on antituberculosis drugs and/or antiretroviral therapy) were excluded.

\section{Sample Size Determination and Sampling Technique}

Data were collected from three wards of the hospital. Since no similar study has been conducted so far, we took the proportion $(P)$ of $50 \%$ and a single proportional sample determination formula was used to estimate the study sample size of the present study.

The formula is given by:

$$
n=\frac{\left(Z_{\alpha / 2}\right)^{2} P(1-P)}{d^{2}}
$$

where $n=$ required initial sample size, $Z_{\alpha / 2}=$ critical value for normal distribution at $95 \%$ confidence interval which equals 1.96 ( $Z$ value at alpha $=0.05), P=$ proportion unsuccessful; $(P=0.5), q=$ proportion of antibiotic use $(q=0.05)$, and $d=$ marginal error $\left(3.5 \%{ }^{2}=0.001225\right)$. To increase the sample size, as recommended in the literature, we used $2.5-5 \%$.

$$
n=\frac{(1.96)^{2} 0.5(1-0.5)}{0.035^{2}}=784
$$

From this single proportion formula, the sample size was 784. Considering a $5 \%$ contingency rate for non-response, the final sample size of the study was 823 patients in the wards of the hospital. Patients were included consecutively using a quota sampling technique. During the study period, 1571 patients were admitted to those wards. Of those, we included 822 patients who were on at least one antibiotic (with a $99.88 \%$ response rate) in our analysis.

\section{Study Variables}

The dependent variable of this study is the antibiotic prescribing pattern (WHO indicators). The independent variables are socio-demographics (age, gender, and residence), reason for admission and comorbid conditions, antibiotic information (frequency, indication, and regimen/combination), and pattern of culture and sensitivity testing.

\section{Data Collection Tools and Procedure}

Data were collected following the pre-tested structured questionnaire and standard antibiotic prescribing indicators generated by the WHO, and we used a questionnaire adapted from similar studies. ${ }^{1,6,27}$ Indicators are categorized into prescribing indicators, hospital indicators, patient care indicators, and complementary indicators. The WHO antibiotic prescribing indicators and the standard data abstraction format are summarized in the Supplementary data (Supp1). 
Data were collected from hospitalized patients as they presented for treatment on the days of the study period. Data were collected consecutively using a standard data abstraction format. Patients admitted during this period were strictly followed. The data that were abstracted from patients' medical charts included: patients' socio-demographic characteristics; diagnosis/reason for admission; dosage form and route of administration; frequency, indication, and duration of prescribed antibiotic; type and number of prescribed antibiotics; and provision of routine laboratory results for monitoring, such as antibiotic sensitivity tests. During the study period, patients' medical charts were reviewed on a daily basis and any change either in the drug chart or in the laboratory details was collected.

The prescription pattern of antibiotics was evaluated using the Ethiopian Essential Medicines List (EML). Six pharmacists were recruited. Three of them were recruited as supervisors and the other three were data collectors.

\section{Data Processing and Statistical Analysis}

Variables were coded, and the database was set and data were entered using EpiData Manager and EpiData Entry Client Version 4.0.2.00, respectively. ${ }^{28}$ Then, data were exported into SPSS version 22.0 for statistical analysis. Descriptive statistics, including mean and standard deviation for continuous variables and frequency and percentage for categorical variables, were used to summarize socio-demographic and relevant clinical characteristics of the study patients and the prescribing pattern of antibiotics. Confidence intervals (CIs) were calculated to compare the prescribing patterns and level of antibiotics. The prescribing patterns of antibiotics were calculated, evaluated, and interpreted against the standard values of WHO prescribing indicators. ${ }^{1,6}$ Details regarding the calculation formulae are summarized in the Supplementary data.

\section{Data Quality Control}

A pre-test was performed on $5 \%$ of the sample a week before the actual data collection commenced, and amendments were made accordingly. Training was provided for the data collectors and close supervision was executed on a daily basis. At the end of each data collection day, completeness of the filled information was checked to ensure the quality of the recorded data. An immediate correction was made, if any mistakes were found.

\section{Operational Definitions}

\section{Antibiotics}

Antibiotics are drugs that are provided for the treatment of different infections due to different species of bacteria. Antibiotics are medicines used to prevent and treat bacterial infections. ${ }^{29}$

\section{Antibiotic Resistance (ABR)}

ABR is the ability of a microorganism to stop the antibiotic from working against it or failure of the drug to inhibit the growth of a microorganism at clinically achievable concentration. ${ }^{30}$

\section{Antibiotic Stewardship Program (ASP)}

An ASP is a harmonized program that promotes the appropriate prescribing pattern and use of antibiotics to improve patient outcomes, reduces microbial resistance, and decreases the spread of infections. ${ }^{831-34}$

\section{Results}

\section{Socio-Demographic Characteristics}

Out of 1571 patients approached, 822 were found to be on at least one antibiotic and were included in the study. The mean \pm SD age of patients was $34.2 \pm 9.55$ years. The majority $(60.6 \%)$ of patients were female. The socio-demographic characteristics of participants are described in Table 1.

\section{WHO Indicators \\ Prescribing Indicators}

Out of 1571 inpatients in the hospital, a total of 1653 antibiotics were prescribed for $822(52.3 \%, 95 \%$ CI $48.2-54.4 \%)$ patients. The average (mean $\pm \mathrm{SD}$ ) number of prescribed antibiotics per patient was found to be $2.01 \pm 1.9$, with the highest value (four antibiotics) being observed on the surgical ward for a mean $\pm \mathrm{SD}$ duration of $4.2 \pm 2.3$ days, and the longest duration (11 days) being observed on the medical ward. Furthermore, the percentages of antibiotics prescribed from the EML of Ethiopia and using their generic name were $100 \%$ and $97.6 \%$, respectively. Details regarding prescribing indicators are summarized in Table 2. All antibiotics were prescribed empirically in all cases, as culture and sensitivity testing of antibiotics was not carried out at all in the hospital. Half $(50.1 \%)$ of the antibiotics were prescribed for therapeutic indicationsand $44.4 \%$ for prophylactic purposes. The majority (73.7\%) of inpatients on the surgical ward received antibiotics for prophylaxis. Almost all (96.2\%) of the patients on the medical ward received antibiotics for therapeutic purposes, mainly $(41.2 \%)$ for the treatment of 
Table I Socio-Demographic Characteristics of Patients Admitted to AKU-CSH, Aksum, Northern Ethiopia, 2020

\begin{tabular}{|c|c|c|c|c|c|c|}
\hline \multirow[t]{2}{*}{ Variable } & \multirow[t]{2}{*}{ Category } & \multicolumn{3}{|c|}{ Included Wards $(\mathrm{N}=822)$} & \multirow{2}{*}{$\begin{array}{l}\text { Total Frequency } \\
\text { (\%) }\end{array}$} & \multirow{2}{*}{$\begin{array}{l}\text { Proportion }(95 \% \\
\text { Cl) }\end{array}$} \\
\hline & & $\begin{array}{l}\text { Surgical } \\
(n=384)\end{array}$ & $\begin{array}{l}\text { Medical } \\
(n=3 \mid 3)\end{array}$ & $\begin{array}{l}\text { Gyn/Obs } \\
(n=125)\end{array}$ & & \\
\hline \multirow[t]{2}{*}{ Gender } & Female & $202(40.6)$ & $|7|(34.3)$ & $125(25.1)$ & $498(60.6)$ & $50.2-71.3 \%$ \\
\hline & Male & $182(56.2)$ & $142(43.8)$ & - & $324(39.4)$ & $31.3-47.2 \%$ \\
\hline Age (years) & Mean \pm SD & $3 I \pm I I . I$ & $36 \pm 10.2$ & $25 \pm 9.3$ & $34.2 \pm 8.31$ & \\
\hline \multirow{3}{*}{$\begin{array}{l}\text { Marital } \\
\text { status }\end{array}$} & Never & $101(50.8)$ & $98(49.2)$ & - & $199(24.2)$ & $23.1-25.1$ \\
\hline & married & & & & & \\
\hline & Ever married & $283(45.4)$ & $215(34.5)$ & $125(20.1)$ & $623(75.8)$ & 73. I-78.2 \\
\hline \multirow[t]{2}{*}{ Residence } & Rural & $276(48.3)$ & $232(40.6)$ & $64(11.2)$ & $572(69.6)$ & $67.2-72.1$ \\
\hline & Urban & $108(43.2)$ & $81(32.4)$ & $61(24.4)$ & $250(30.4)$ & $28.2-31.8$ \\
\hline
\end{tabular}

Abbreviations: AKU-CSH, Aksum University College of Health Sciences and Comprehensive Specialized Hospital; Gyn/Obs, gynecology/obstetrics.

pneumonia. Injection was the most common route of antibiotic administration, used in $84.8 \%$ of adult patients.

\section{Hospital and Patient Care Indicators}

The hospital had a copy of the national Formulary List (FL), which contains 54 generic antibiotics. ${ }^{35}$ The hospital also had a Drug and Therapeutic Committee (DTC), but this was not fully functional. No Standard Treatment Guideline (STG) or hospital FL of medicines, particularly for infectious diseases, existed in the hospital. During the study period, $65.2 \%$ of the antibiotics were found to be available in stock. In addition, the average number of days that key antibiotics were out of stock was found to be 3.8 days per month (Table 3).

\section{Complementary Indicators}

Patients took antibiotics for an average (mean \pm SD) of $4.2 \pm 2.3$ days during their hospital stay. The majority (60.2\%) of antibiotics were prescribed for a duration of greater than 7 days. Nearly one-quarter $(24.8 \%)$ of the patients took antibiotics for 5-7 days, and $9.9 \%$ for less than 3 days. Results for the complementary indicators are summarized in Figure 1.

\section{Distribution of Prescribed Antibiotics}

As shown in Table 4, more than half (58.9\%) of antibiotics were prescribed for patients admitted to the surgical ward. Ceftriaxone was the most commonly prescribed antibiotic on most wards, accounting for $24.5 \%$. Ampicillin was the most frequently prescribed antibiotic on the gynecology/ obstetrics ward as prophylaxis, whereas azithromycin $(12.9 \%)$ was the commonest antibiotic prescribed on the medical ward, as community-acquired pneumonia (CAP) was a common reason for admission. The most frequently prescribed combination was ceftriaxone with vancomycin (31.4\%), followed by azithromycin with ceftriaxone (26.8\%). Nearly half (49\%) of the patients received a single antibiotic, whereas $39 \%$ of patients were treated with combination antibiotics (Figure 2).

\section{Discussion}

In the present study, the prescribing pattern of antibiotics has been evaluated using WHO prescribing indicators at three selected wards of AKU-CSH, providing a way forward to establish an ASP for intervention. Therefore, this study sought to determine a comprehensive and better exemplification of antibiotic prescribing practice in selected wards of the hospital and straighten the likelihood of prescribing practice being oversight. Our hospital lacks its own institutional STG and its own FL of medicines. Furthermore, culture and sensitivity tests for common microorganisms were non-existent.

In our study, the overall antibiotic prescribing rate was found to be $52.3 \%$ (95\% CI 48.2-54.4\%) of patients within the study period. This finding exceeded the standard endorsed by WHO of $20-25.4 \% .{ }^{1}$ This shows a high rate of antibiotic prescription in our hospital. This figure was similar to those observed in previous studies, including $48.5 \%$ in Gondar town, Ethiopia, ${ }^{36} 55.2 \%$ in Ghana, ${ }^{37} 51.0 \%$ in Nigeria, ${ }^{38}$ $51.5 \%$ in Pakistan, ${ }^{39}$ and $54.6 \%$ in China. ${ }^{40}$ On the other hand, our prescribing rate of antibiotics was low compared to the results reported from other studies conducted in southwest Ethiopia (64.7\%), ${ }^{41}$ southern Ethiopia $(58.1 \%),{ }^{23}$ and Harar, eastern Ethiopia (66.9\%). ${ }^{42}$ Similarly, it was also lower than in studies reported from Eritrea $(79.05 \%$ and $69 \%),{ }^{27,43}$ Congo $(68 \%),{ }^{44}$ India $(66 \%),{ }^{45}$ and Pakistan $(82.3 \%)^{6}$ 
Table 2 WHO Prescribing Indicators of Antibiotics Among Patients Admitted to AKU-CSH, Aksum, Northern Ethiopia, 2020

\begin{tabular}{|c|c|c|c|c|c|c|}
\hline \multirow[t]{2}{*}{ Prescribing Indicator } & \multicolumn{3}{|c|}{ Selected Wards, n (\%) [N=|57I] } & \multirow{2}{*}{$\begin{array}{l}\text { Total, } \mathrm{n}=822 \mathrm{n}(\%) \\
\text { mean } \pm \text { SD }\end{array}$} & \multirow{2}{*}{$\begin{array}{l}\text { Proportion } \\
(95 \% \mathrm{CI})\end{array}$} & \multirow{2}{*}{$\begin{array}{l}\text { Ideal } \\
\text { Value }^{1,6,27}\end{array}$} \\
\hline & Surgical & Medical & Gyn/Obs & & & \\
\hline $\begin{array}{l}\text { Percentage of patients admitted with at least one } \\
\text { antibiotic }\end{array}$ & $384(46.7)$ & $313(38.1)$ & $125(15.2)$ & $822(52.3)$ & $48.2-54.4$ & $20-26$ \\
\hline Average number of antibiotics prescribed per patient & $974(2.54)$ & $491(1.57)$ & $188(1.53)$ & $2.01 \pm 1.9$ & - & $1.6-1.8$ \\
\hline $\begin{array}{l}\text { Percentage of antibiotics prescribed from national FL/ } \\
\text { EML }\end{array}$ & $974(100)$ & $491(100)$ & $188(100)$ & $1653(100)$ & - & 100 \\
\hline Percentage of antibiotics prescribed by generic name & $969(99.5)$ & $461(93.9)$ & $183(97.3)$ & $1613(97.6)$ & $94-99.1$ & 100 \\
\hline Percentage of antibiotics prescribed in injection form & $879(53.2)$ & $360(21.8)$ & $163(9.9)$ & $1402(84.8)$ & $82.5-87.1$ & |3.4-24.| \\
\hline Percentage of antibiotics prescribed in oral form & $95(5.7)$ & $|3|$ (7.9) & $25(1.5)$ & $25 I(15.2)$ & $12.8-17.1$ & \\
\hline $\begin{array}{l}\text { Average duration of days antibiotic prescribed in the } \\
\text { hospital stay }\end{array}$ & 4.2 & 6.8 & 1.5 & $4.2 \pm 2.3$ & - & - \\
\hline $\begin{array}{l}\text { Percentage of patients who received antibiotics for } \\
\text { therapeutic purpose }\end{array}$ & $76(19.8)$ & $301(96.2)$ & $35(28.0)$ & $4 \mid 2(50.1)$ & $58.7-64.6$ & - \\
\hline $\begin{array}{l}\text { Percentage of patients who received antibiotics for } \\
\text { prophylactic purpose }\end{array}$ & $283(73.7)$ & $7(2.2)$ & $75(60.0)$ & $365(44.4)$ & $29.5-34.3$ & - \\
\hline $\begin{array}{l}\text { Percentage of patients who received antibiotics for } \\
\text { unknown purpose }\end{array}$ & $25(6.5)$ & $5(1.6)$ & $15(12.0)$ & $45(5.5)$ & $4.4-7.1$ & 0 \\
\hline $\begin{array}{l}\text { Percentage of patients who received antibiotics for } \\
\text { empiric therapy }\end{array}$ & $101(100)$ & $306(100)$ & $50(100)$ & $457(100)$ & - & - \\
\hline
\end{tabular}

Abbreviations: AKU-CSH, Aksum University, College of Health Sciences and Comprehensive Specialized Hospital; Gyn/Obs, gynecology and obstetrics; FL/EML, Formulary List/Essential Medicine List.

Table 3 Hospital and Patient Indicators for Prescribing Antibiotics for Patients Admitted to AKU-CSH, Aksum, Northern Ethiopia, 2020

\begin{tabular}{|l|l|l|}
\hline Hospital Indicator & Results & Recommended \\
\hline $\begin{array}{l}\text { Existence of DTC } \\
\text { Existence of copy of national STGs } \\
\text { for tertiary hospitals } \\
\text { Existence of institutional STGs/ } \\
\text { clinical guideline for infectious } \\
\text { diseases } \\
\text { Existence of a copy of national FL/ } \\
\text { EML }\end{array}$ & 0 & $\mathrm{I}$ \\
$\begin{array}{l}\text { Existence of institutional FL/EML } \\
\text { Availability of a set of key antibiotics } \\
\text { in the hospital in the study period } \\
\text { Average number of days that a set of } \\
\text { key antibiotics is out of stock/month } \\
\text { Number of sensitivity tests } \\
\text { performed for the prescribed } \\
\text { antibiotics }\end{array}$ & 3.8 & 0 \\
\hline
\end{tabular}

Note: Yes $=$ I, $\mathrm{No}=0$.

Abbreviations: DTC, Drug and Therapeutics Committee; STG, Standard Treatment Guideline; FL/EML, Formulary List/Essential Medicine List.

On the other hand, our result for the percentage of patients on at least one prescribed antibiotic was higher than rates of $32.0 \%$ reported in Ayder hospital, northern Ethiopia, ${ }^{26} 24.37 \%$ in Welo town, Ethiopia, ${ }^{46} 29.4 \%$ in Gondar hospital, Ethiopia, ${ }^{47}$ and $36.71 \%$ in Cameroon. ${ }^{48}$
This discrepancy could be explained by the fact that these studies investigated outpatients, taking oral antibiotics only, and were conducted in the community, compared to our study which was conducted only on hospitalized patients and reported both oral and parenteral antibiotics. Furthermore, these studies evaluated the prescribing pattern of antibiotics for a shorter duration (no longer than 6 months), compared to our work with a period of 11 months (nearly 1 year). In addition, some of the studies were conducted on surgical wards, with an antibiotic utilization rate of $69 \%,{ }^{43}$ and included all drugs in Ayder, Ethiopia, ${ }^{26}$ while other studies were conducted on outpatients, with a rate of $58 \%$ in Hawassa, Ethiopia, ${ }^{23}$ and in primary health care in Saudi Arabia. ${ }^{49}$

Moreover, the average number (2.01) of antibiotics per patient in our study exceeded the standard recommended by the WHO, with a limit of $1.6-1.8,{ }^{1}$ showing that prescription pattern of antibiotics in the study area was similar to the 2.1-2.2 antibiotics per patient reported in other studies conducted in eastern Ethiopia and Addis Ababa. ${ }^{42,50}$ On the other hand, our finding was higher than the optimal values and lower than findings reported from Eritrea and Congo, in which 1.29 and 1.4 antibiotics per patient were prescribed, respectively. ${ }^{27,44}$

A striking finding from our study was that all $(100 \%)$ of the prescribed antibiotics were from the EML of 


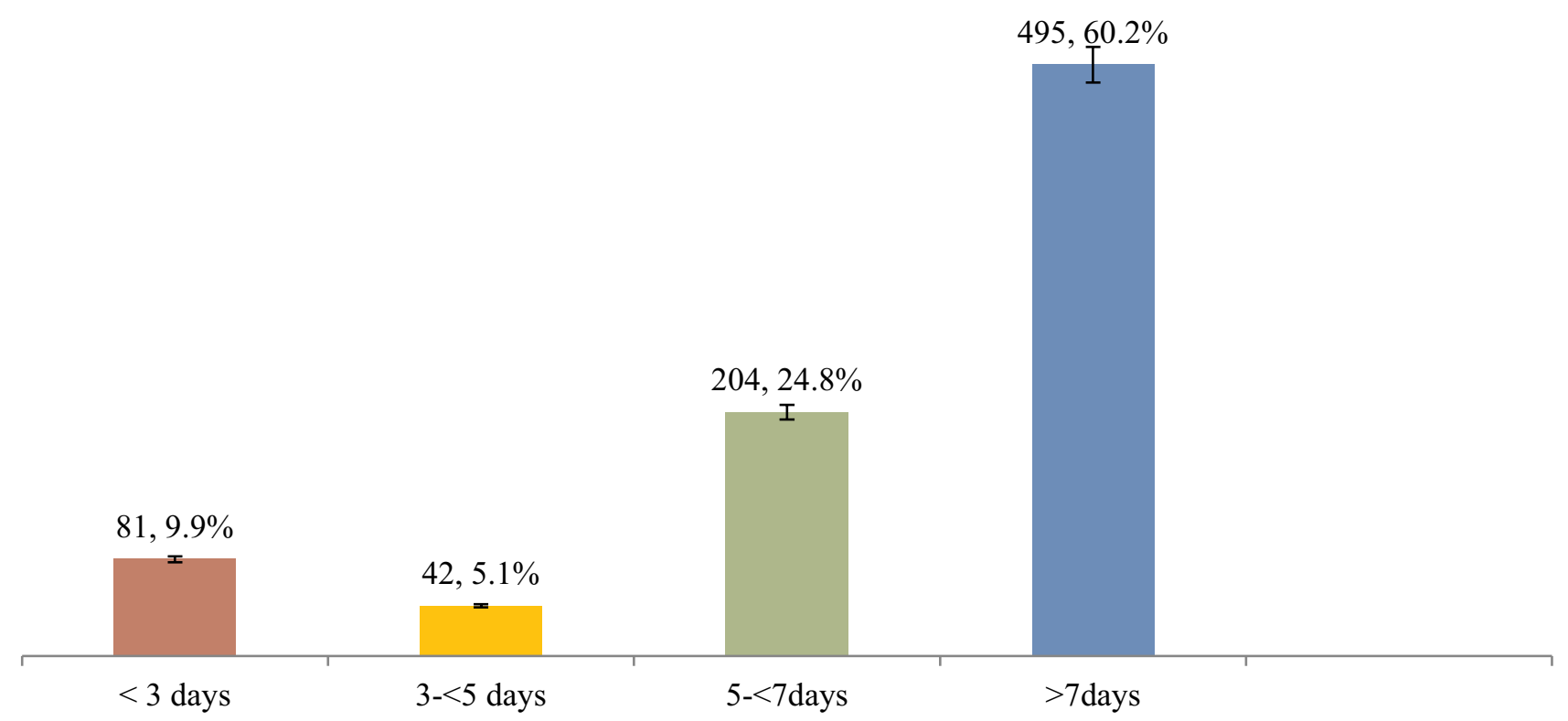

Figure I Number of days prescribed antibiotics for patients admitted to selected wards of AKU-CSH, Aksum, northern Ethiopia, 2020.

Ethiopia. ${ }^{35}$ This is consistent with the study conducted in Eritrea, ${ }^{27}$ in which all $(100 \%)$ of antibiotics were prescribed from the national EML. This could be explained by the fact that public hospitals in Ethiopia procure most of their medicines from the government supplier, which predominantly supplies medicines based on the national EML. Hence, prescribers in AKU-CSH are stimulated to stick to the EML, resulting in full compliance with the EML. Many studies have demonstrated deviations from meeting the target endorsed by their national EML; for example, $79 \%$ in Lesotho, ${ }^{51} 98.8 \%$ in Pakistan, ${ }^{39} 99.8 \%$ in India, ${ }^{52}$ and $67.1 \%$ in Nepal. ${ }^{53}$ Our finding adhered to the standard value endorsed by the WHO, in that $100 \%$ of antibiotics were prescribed from the EML. ${ }^{54}$ Our study was conducted in a tertiary hospital, where the antibiotic options may not be limited to the national STG and physicians may manage their patients based on their expertise.

Another major finding from our study was that injectable antibiotics were frequently prescribed, at a rate of $84.8 \%$. This is comparable to $81.4 \%$ in a study in Asmara, Eritrea, ${ }^{27}$ and $82.4 \%$ in Addis Ababa, Ethiopia, ${ }^{50}$ but higher than $68.2 \%$ in Congo. ${ }^{44}$ Other studies conducted in Ethiopia have reported lower rates of injections being prescribed, at $11.2 \%,{ }^{25} 26.5 \%,{ }^{42}$ and $38 \% .{ }^{23}$ Those studies conducted on outpatients, in particular, could account for the lower percentage of injections being prescribed. In our study, it is likely that injectable antibiotics were commonly prescribed because they are reserved for hospitalized patients, and in the context of this study, such patients would be managed on wards, whereas outpatients were not included in our study. Overprescribing injectable antibiotics is considered a case of inappropriate antibiotic use. ${ }^{39,55}$ Therefore, prescribers in AKU-CSH need to emphasize replacing injectable antibiotics by the oral route, to reduce injection-related infections, shorten hospital stay, and decrease health-care costs. ${ }^{56}$ This may indicate that prescribers know that they should not give as many injections as they do.

Out of 54 key antibiotics assessed from Ethiopia's national $\mathrm{EML}^{35}$ during the study period, the stock availability of key antibiotics in AKU-CSH was found to be $65.2 \%$. A comparable result $(65.7 \%)$ has been reported in southern Ethiopia. ${ }^{57}$ Although our finding was lower than that reported in other studies, showing stock availability of key antibiotics of $72.4 \%$ in Pakistan, ${ }^{39} 87.5 \%$ in Eritrea, ${ }^{27}$ $81.3 \%$ in Sudan, ${ }^{58}$ and $83.3 \%$ in Zambia, ${ }^{59}$ these values are much lower than the ideal value as key antibiotics should always be available. ${ }^{1}$

This result may imply a shortage of key antibiotics, which will influence prescribers in prescribing antibiotics with less effectiveness, higher costs, and greater resistance. In the study area, key antibiotics were out of stock for 3.8 days per month, which is considerably higher than the 30 days per year reported in another study in Ethiopia, ${ }^{60}$ but lower than 6.52 days per month $(78.18$ 
Table 4 Distribution of Antibiotics Prescribed for Patients Admitted to Selected Wards of AKU-CSH, Aksum, Northern Ethiopia, 2020

\begin{tabular}{|c|c|c|c|c|c|}
\hline \multirow[t]{2}{*}{ Antibiotics } & \multicolumn{3}{|c|}{ Involved Wards, n (\%) } & \multirow{2}{*}{$\begin{array}{l}\text { Total, } \\
\text { n (\%) }\end{array}$} & \multirow{2}{*}{$\begin{array}{l}\text { Proportion }(95 \% \\
\mathrm{Cl})\end{array}$} \\
\hline & $\begin{array}{l}\text { Surgical } \\
(n=384)\end{array}$ & $\begin{array}{l}\text { Medical } \\
(n=3 \mid 3)\end{array}$ & $\begin{array}{l}\text { Gyn/Obs } \\
(n=125)\end{array}$ & & \\
\hline Ampicillin injection & $5(0.5)$ & $0(0.0)$ & $87(46.3)$ & $92(5.6)$ & $3.8-6.9$ \\
\hline Amoxicillin-clavulanic acid tablet & $85(8.7)$ & $72(14.7)$ & $5(2.7)$ & $162(9.8)$ & $7.4-11.2$ \\
\hline Amoxicillin capsule & $39(4.0)$ & $101(20.6)$ & II (5.9) & $15 \mid(9.1)$ & $8.1-9.9$ \\
\hline Crystalline penicillin injection & $21(2.2)$ & $0(0.0)$ & $\mathrm{I}(0.5)$ & $22(1.3)$ & $1.1-1.8$ \\
\hline Cloxacillin injection/capsule & $12(1.2)$ & $0(0.0)$ & $2(1.1)$ & $14(0.8)$ & $0.2-1.1$ \\
\hline Ceftriaxone injection & $255(26.2)$ & $79(16.1)$ & 71 (37.8) & $405(24.5)$ & $22.7-26.3$ \\
\hline Cephalexin capsule & $84(8.6)$ & $2(0.4)$ & $9(4.8)$ & $95(5.7)$ & $4.5-6.6$ \\
\hline Ceftazidime injection & $14(1.4)$ & $2(0.4)$ & $0(0.0)$ & $16(1.0)$ & $0.6-1.2$ \\
\hline Ciprofloxacin injection & $8(0.8)$ & $0(0.0)$ & $0(0.0)$ & $8(0.5)$ & $0.1-0.9$ \\
\hline Cefepime injection & $65(6.7)$ & $25(5.1)$ & $0(0.0)$ & $90(5.4)$ & $4.1-6.3$ \\
\hline Vancomycin injection & $202(20.7)$ & $17(3.5)$ & $0(0.0)$ & $219(13.2)$ & $12.1-14.3$ \\
\hline Gentamycin injection & $6(0.6)$ & $0(0.0)$ & $2(1.1)$ & $8(0.5)$ & $0.1-0.9$ \\
\hline Metronidazole injection & $126(12.9)$ & $31(6.3)$ & $0(0.0)$ & $157(9.5)$ & $8.3-10.1$ \\
\hline Azithromycin capsule & $52(5.3)$ & $162(33)$ & $0(0.0)$ & $214(12.9)$ & $11.6-13.8$ \\
\hline Total & $974(58.9)$ & $491(29.7)$ & $188(11.4)$ & $1653(100)$ & \\
\hline \multicolumn{6}{|l|}{ Combination } \\
\hline Metronidazole + ciprofloxacin & $5(1.7)$ & $0(0.0)$ & $0(0.0)$ & $5(1.2)$ & $0.9-1.6$ \\
\hline Azithromycin + ceftriaxone & $32(11.0)$ & $81(63.3)$ & $0(0.0)$ & $113(26.8)$ & $24.1-27.9$ \\
\hline Ceftriaxone + vancomycin & $130(44.7)$ & $2(1.6)$ & $0(0.0)$ & $132(3 \mid .4)$ & $28.3-32.8$ \\
\hline Metronidazole + vancomycin & $55(18.9)$ & $15(11.7)$ & $0(0.0)$ & $70(16.6)$ & $15.1-17.3$ \\
\hline Ciprofloxacin + vancomycin & $3(1.0)$ & $0(0.0)$ & $0(0.0)$ & $3(0.7)$ & $0.2-0.9$ \\
\hline Ceftazidime + vancomycin & $14(4.8)$ & $2(1.6)$ & $0(0.0)$ & $16(3.8)$ & $2.2-4.3$ \\
\hline Ceftriaxone + gentamycin & $\mathrm{I}(0.3)$ & $0(0.0)$ & $\mathrm{I}(0.5)$ & $2(0.5)$ & $0.1-0.9$ \\
\hline Ampicillin + gentamycin & $5(1.7)$ & $0(0.0)$ & $\mathrm{I}(0.5)$ & $6(1.4)$ & $1.1-1.9$ \\
\hline Ceftriaxone + metronidazole & $26(8.9)$ & $16(12.5)$ & $0(0.0)$ & $42(10.0)$ & $8.8-11.7$ \\
\hline $\begin{array}{l}\text { Azithromycin + amoxicillin-clavulanic } \\
\text { acid }\end{array}$ & $20(6.9)$ & $12(9.4)$ & $0(0.0)$ & $32(7.6)$ & $6.1-8.3$ \\
\hline
\end{tabular}

Abbreviations: AKU-CSH, Aksum University College of Health Sciences and Comprehensive Specialized Hospital; Gyn/Obs, gynecology/obstetrics.

days per year) in Eritrea. ${ }^{27}$ The implication of this finding, that key antibiotics were not available for 3.8 days per month, warrants consideration by policy-makers, who may need to put legislation in place to ensure better access to these key essential drugs.

Another finding in our study was that patients took antibiotics for an average (mean $\pm \mathrm{SD}$ ) of $4.2 \pm 2.3$ days during their hospital stay, which is shorter than the standard duration of antibiotic use. However, the majority $(60.2 \%)$ of patients were on antibiotics for a duration of longer than 7 days while nearly one-quarter $(24.8 \%)$ of patients were taking them for 5-7 days and $9.9 \%$ for less than 3 days. This figure is lower than in a similar study conducted in Eritrea, ${ }^{27}$ which reported that antibiotics were prescribed for a duration of 6.36 days. But $13.1 \%$ of patients were taking antibiotics for longer than 10 days. Shorter or longer durations of antibiotic use in the hospital require emphasis and this may improve by developing an institutional guideline.

We also found that just $96.7 \%$ of antibiotics were prescribed by the generic name, despite the aim being that $100 \%$ of antibiotics should be prescribed by their generic name. According to the WHO indicators, ${ }^{1}$ prescribing antibiotics by their generic name is one of the straightforward indicators of using low-cost antibiotics. In the present work, $96.7 \%$ of antibiotics were prescribed by their generic name. This was slightly lower than the standard $(100 \%)$ endorsed by the WHO for prescribing drugs by their generic name. ${ }^{1}$ However, this result was higher than the rates of $49.3 \%$ and $56.1 \%$ found in studies conducted in Sudan ${ }^{58}$ and Zambia, ${ }^{59}$ respectively. Furthermore, our findings are similar to the results of $95.8 \%$ from a study in Sidama, Ethiopia, ${ }^{22}$ $98.36 \%$ in Cameroon, ${ }^{48}$ and $97 \%$ in Eritrea. ${ }^{27}$ 


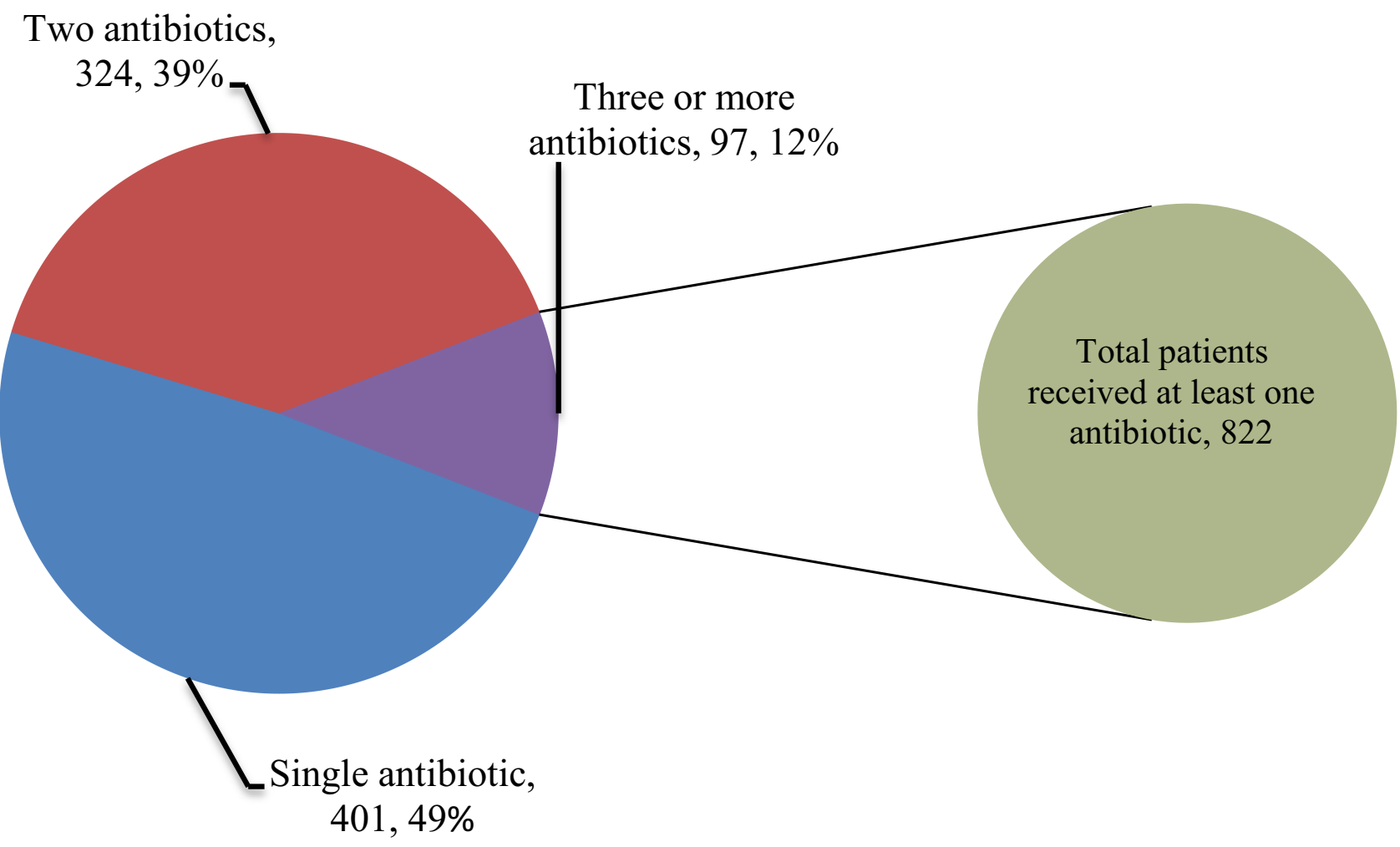

Figure 2 Numbers of prescribed antibiotics per prescription for patients admitted to selected wards of AKU-CSH, Aksum, northern Ethiopia, 2020.

In fact, prescribing antibiotics by their brand and generic name has no variance in terms of pharmacological efficacy. ${ }^{61}$ This could be justified since prescribing drugs by their generic name decreases the odds of drug replication, as patients may lack knowledge on the use of the same drug when one physician prescribes a brand name and another a generic name, or both may use different brand names. However, there may be differences in understanding and views on the variation between generic and brand names. ${ }^{62}$ Hence, the prescribing of antibiotics by generic names in our setting shows a good practice of antibiotic prescription and should be encouraged.

In our study, more 14 types of antibiotics were prescribed as single drugs or in combination. A notable finding was that culture and local sensitivity testing of antibiotics are not performed in our hospital, and thus all antibiotics were prescribed empirically. Prescription of broad-spectrum antibiotics is not uncommon practice, as shown in similar studies. ${ }^{38-40,50}$ For prescribing broad-spectrum antibiotics, there may be no need for cultures for the isolation of microorganisms. The most commonly prescribed antibiotic was ceftriaxone (24.5\%), followed by vancomycin (13.2\%) and azithromycin (12.9\%). In a similar study in Saudi Arabia, ${ }^{63}$ ceftriaxone was the most commonly prescribed antibiotic. Among hospitalized patients, pneumonia (azithromycin), suspected methicillin resistance (vancomycin), surgical site infection, and gynecological cases (ceftriaxone) were suggested as conceivable explanations for antibiotic utilization. The prescribing of such antibiotics has also been reported in other tertiary and primary health-care settings in Ethiopia. ${ }^{23,41,50,57,60}$

However, in studies reported from southern and eastern Ethiopia, ${ }^{22,42}$ Zambia, ${ }^{59}$ and Cameroon, ${ }^{48}$ amoxicillin was the most commonly prescribed antibiotic, whereas in Eritrea and Congo ${ }^{27,44}$ ampicillin (injection) was the most frequently prescribed. This discrepancy may be explained by the fact that our work was conducted in a tertiary hospital, where all prescribers are at least general practitioners who may prescribe antibiotics with lower resistance data to control complicated medical problems in patients referred from different primary health-care settings. In addition, studies conducted on outpatients in Cameroon, ${ }^{38}$ and southern and eastern Ethiopia $^{41,42}$ indicated that it may be feasible to prescribe amoxicillin as an oral antibiotic.

\section{Limitations of the Study}

Our study has certain limitations. As the prescribing antibiotics pattern was investigated in a single hospital, the results of the study cannot be generalized to all hospitals in 
Ethiopia, and as this study was conducted among inpatients it may not represent outpatients. Furthermore, as very limited data on core antibiotic prescribing indicators are available among inpatients, we compared our findings with data based on results from outpatients.

\section{Conclusions}

Our study evaluated the prescribing pattern of antibiotics by generic name, the availability of STGs and compliance, days on which antibiotics were out of stock, and availability of antibiotic sensitivity testing. In this study, more than half of patients were on at least one prescribed antibiotic and all antibiotics were prescribed from the EML of Ethiopia. However, all antibiotics were prescribed without culture and sensitivity tests, in all cases. This result shows that the prescribing pattern of antibiotics in the hospital deviates from and is non-compliant with the standard endorsed by the WHO. This problem may be reduced by developing an ASP, introducing the practice of antibiotics with the aid of culture and sensitivity tests, and developing institutional guidelines. Therefore, this study provides evidence for the necessity and a way forward for the establishment of an ASP in the hospital.

\section{Abbreviations}

ABR, antibiotic resistance; AKU-CSH, Aksum University Comprehensive Specialized Hospital; ASP, Antibiotic Stewardship Program; CDC, Centers for Disease Control and Prevention; DTC, Drug and Therapeutics Committee; EML, Essential Medicine List; FL, Formulary List; IRB, Institutional Review Board; STG, Standard Treatment Guideline; WHO, World Health Organization.

\section{Data Sharing Statement}

All data used in this study supplied with the manuscript and Supplementary data can be obtained from the corresponding author upon request when needed.

\section{Ethics Approval}

Ethical clearance and approval was obtained from the Institutional Review Board (IRB) of Aksum University prior to data collection, with a declaring review board reference number of IRB090/2019. Subsequently, a support letter was secured from the medical director of Aksum University Comprehensive Specialized Hospital (AKU-CSH). The methods were carried out in accordance with the relevant guidelines and regulations of the IRB of the University. Our study was conducted in accordance with the Declaration of
Helsinki. Written informed consent was obtained from each participant before conducting this study. Participants' information was kept confidential. The right of patients to withdraw or not to participate was respected. Before commencing the study, the aim of the study was explained to each participant. Privacy and confidentiality were kept by eliminating identifiers and curbing data access, respectively.

\section{Acknowledgments}

The authors would like to acknowledge Aksum University for granting this project. In particular, our heartfelt gratitude goes to all the data collectors and staffs in all wards of the hospital. Finally, we extend our appreciation to all the study participants for their time and their insights.

\section{Author Contributions}

All authors made substantial contributions to conception and design, acquisition of data, or analysis and interpretation of data; took part in drafting the article or revising it critically for important intellectual content; gave final approval of the version to be published; and agree to be accountable for all aspects of the work.

\section{Funding}

This study was funded by Aksum University (grant number: AKU00041/2011). The funder had no role in the design, analysis, or interpretation of the study.

\section{Disclosure}

The authors declare that they have no competing interests.

\section{References}

1. WHO. How to Investigate Antimicrobial Use in Hospitals: Selected Indicators. World Health Organization; 2012.

2. Cantas L, Shah SQA, Cavaco LM, et al. A brief multi-disciplinary review on antimicrobial resistance in medicine and its linkage to the global environmental microbiota. Front Microbiol. 2013;4:96. doi:10.3389/fmicb.2013.00096

3. Davies J, Davies D. Origins and evolution of antibiotic resistance. Microbiol Mol Biol Rev. 2010;74(3):417-433. doi:10.1128/ MMBR.00016-10

4. Organization WH. Global antimicrobial resistance surveillance system (GLASS) report: early implementation 2016-2017. Global antimicrobial resistance surveillance system (GLASS) report: early implementation 2016-2017. 2017.

5. WHO. Worldwide Country Situation Analysis: Response to Antimicrobial Resistance. World Health Organization (WHO); 2015.

6. Atif M, Azeem M, Saqib A, Scahill S. Investigation of antimicrobial use at a tertiary care hospital in Southern Punjab, Pakistan using WHO methodology. Antimicrob Resist Infect Control. 2017;6(1):41. doi:10.1186/s13756-017-0199-7 
7. CDC. Antibiotic prescribing and use in doctor's office. CDC, 2017. Available from: https://www.cdc.gov/antibiotic-use/community/ index.html. Accessed July 23, 2020.

8. CDC. Core elements of hospital antibiotic stewardship programs? Antibiotic use/CDC. 2019. Available from: https:/www.cdc.gov/anti biotic-use/core-elements/hospital.html?CDC AA refVal=https $\% 3 \mathrm{~A}$ $\% 2$ F $\% 2$ Fwww.cdc.gov $\% 2$ Fantibiotic-use $\% 2$ Fhealthcare $\%$ 2Fimplementation\%2Fcore-elements.html. Accessed July 23, 2020.

9. Dyar OJ, Huttner B, Schouten J, Pulcini C. What is antimicrobial stewardship? Clin Microbiol Infect. 2017;23(11):793-798. doi:10.1016/j.cmi.2017.08.026

10. Manning ML. The urgent need for nurse practitioners to lead antimicrobial stewardship in ambulatory health care. J Am Assoc Nurse Pract. 2014;26(8):411-413. doi:10.1002/2327-6924.12150

11. Maraolo AE, Ong DSY, Cimen C, et al. Organization and training at national level of antimicrobial stewardship and infection control activities in Europe: an ESCMID cross-sectional survey. Eur J Clin Microbiol Infect Dis. 2019;38(11):2061-2068. doi:10.1007/s10096019-03648-2

12. Barlam TF, Cosgrove SE, Abbo LM, et al. Executive summary: implementing an antibiotic stewardship program: guidelines by the Infectious Diseases Society of America and the Society for Healthcare Epidemiology of America. Clin Infect Dis. 2016;62 (10):1197-1202. doi:10.1093/cid/ciw217

13. Gottlieb T, Nimmo GR. Antibiotic resistance is an emerging threat to public health: an urgent call to action at the antimicrobial resistance summit 2011. Med J Aust. 2011;194(6):281-283. doi:10.5694/j.13265377.2011.tb02973.x

14. Li Q, Zhao G, Wu L, et al. Prevalence and patterns of drug resistance among pulmonary tuberculosis patients in Hangzhou, China Antimicrob Resist Infect Control. 2018;7(1):61. doi:10.1186/s13756018-0348-7

15. Kimang'a AN. A situational analysis of antimicrobial drug resistance in Africa: are we losing the battle? Ethiop J Health Sci. 2012;22(2).

16. Aidara-Kane A, Angulo FJ, Conly JM, et al. World Health Organization (WHO) guidelines on use of medically important antimicrobials in food-producing animals. Antimicrob Resist Infect Control. 2018;7(1):7. doi:10.1186/s13756-017-0294-9

17. Ayukekbong JA, Ntemgwa M, Atabe AN. The threat of antimicrobial resistance in developing countries: causes and control strategies. Antimicrob Resist Infect Control. 2017;6(1):47. doi:10.1186/s13756017-0208-x

18. Williams A, Mathai AS, Phillips AS. Antibiotic prescription patterns at admission into a tertiary level intensive care unit in Northern India. J Pharm Bioallied Sci. 2011;3(4):531. doi:10.4103/0975-7406.90108

19. Storr J, Twyman A, Zingg W, et al. Core components for effective infection prevention and control programmes: new WHO evidence-based recommendations. Antimicrob Resist Infect Control. 2017;6(1):6. doi:10.1186/s13756-016-0149-9

20. Yallew WW, Kumie A, Yehuala FM. Point prevalence of hospital-acquired infections in two teaching hospitals of Amhara region in Ethiopia. Drug Healthc Patient Saf. 2016;8:71. doi:10.2147/DHPS.S107344

21. Woldu MA, Suleman S, Workneh N, Berhane H. Retrospective study of the pattern of antibiotic use in Hawassa University referral hospital pediatric ward, Southern Ethiopia. J Appl Pharm Sci. 2013;3(2):93.

22. Summoro TS, Gidebo KD, Kanche ZZ, Woticha EW. Evaluation of trends of drug-prescribing patterns based on WHO prescribing indicators at outpatient departments of four hospitals in southern Ethiopia. Drug Des Devel Ther. 2015;9:4551. doi:10.2147/DDDT. S83588

23. Desalegn AA. Assessment of drug use pattern using WHO prescribing indicators at Hawassa University teaching and referral hospital, south Ethiopia: a cross-sectional study. BMC Health Serv Res. 2013;13(1):170. doi:10.1186/1472-6963-13-170
24. Worku F, Tewahido D. Retrospective assessment of antibiotics prescribing at public primary healthcare facilities in Addis Ababa, Ethiopia. Interdiscip Perspect Infect Dis. 2018;2018:1-9. doi:10.1155/2018/4323769

25. Bilal AI, Osman ED, Mulugeta A. Assessment of medicines use pattern using World Health Organization's prescribing, patient care and health facility indicators in selected health facilities in eastern Ethiopia. BMC Health Serv Res. 2016;16(1):144. doi:10.1186/ s12913-016-1414-6

26. Demeke B, Molla F, Assen A, Melkam W, Abrha S, Masresha B. Evaluation of drugs utilization pattern using WHO prescribing indicators in Ayder referral hospital, Northern Ethiopia. IJPSR. 2015;6 (2):343-347.

27. Amaha ND, Berhe YH, Kaushik A. Assessment of inpatient antibiotic use in Halibet National Referral Hospital using WHO indicators: a retrospective study. BMC Res Notes. 2018;11:904. doi:10.1186/ s13104-018-4000-7

28. EpiData Association, att. Jens M.Lauritsen. Enghavevej 34, DK5230 Odense M. Denmark, Europe; 2006.

29. WHO. What-is-the-difference-between-antibiotic-and-antimicrobialresistance 2020 updated January 20. Available from: http://www. emro.who.int/health-topics/drug-resistance/what-is-the-differencebetween-antibiotic-and-antimicrobial-resistance.html. Accessed July 23, 2020.

30. Asgin N, Otlu B. Antibiotic resistance and molecular epidemiology of vancomycin-resistant enterococci in a Tertiary Care Hospital in Turkey. Infect Drug Resist. 2020;13:191-198. doi:10.2147/IDR. S191881

31. Pulcini C, Binda F, Lamkang AS, et al. Developing core elements and checklist items for global hospital antimicrobial stewardship programmes: a consensus approach. Clin Microbiol Infect. 2019;25 (1):20-25. doi:10.1016/j.cmi.2018.03.033

32. Harmon S, Richardson $\mathrm{T}$, Simons $\mathrm{H}$, Monforte S, Fanning S, Harrington K. The clinical and financial impact of a pharmacist-driven penicillin skin testing program on antimicrobial stewardship practices. Hosp Pharm. 2020;55(1):58-63. doi:10.1177/ 0018578718817917

33. Garcia Reeves AB, Lewis JW, Trogdon JG, Stearns SC, Weber DJ, Weinberger M. Association between statewide adoption of the CDC's core elements of hospital antimicrobial stewardship programs and rates of methicillin-resistant Staphylococcus aureus bacteremia and Clostridioides difficile infection in the United States. Infect Control Hosp Epidemiol. 2019;1-8.

34. Kim B, Lee MJ, Moon SM, et al. Current status of antimicrobial stewardship programmes in Korean hospitals: results of a 2018 nationwide survey. J Hosp Infect. 2020;104(2):172-180.

35. FMHACA. List of Medicines for Ethiopia: Food, Medicine and Healthcare Administration and Control Authority of Ethiopia. Vol. 6. FMHACA; 2010.

36. Erku DA, Aberra SY. Non-prescribed sale of antibiotics for acute childhood diarrhea and upper respiratory tract infection in community pharmacies: a 2 phase mixed-methods study. Antimicrob Resist Infect Control. 2018;7(1):92. doi:10.1186/s13756-018-0389-y

37. Prah J, Kizzie-Hayford J, Walker E, Ampofo-Asiama A. Antibiotic prescription pattern in a Ghanaian primary health care facility. Pan Afr Med J. 2017;28(1). doi:10.11604/pamj.2017.28.214.13940

38. Enato EF, Chima IE. Evaluation of drug utilization patterns and patient care practices. West Afr J Pharm. 2011;22(1).

39. Atif M, Sarwar MR, Azeem M, et al. Assessment of WHO/INRUD core drug use indicators in two tertiary care hospitals of Bahawalpur, Punjab, Pakistan. J Pharm Policy Pract. 2016;9:27. doi:10.1186/ s40545-016-0076-4

40. Yan K, Xue M, Ye D, et al. Antibiotic prescribing practices in secondary and tertiary hospitals in Shaanxi province, western China, 2013-2015. PLoS One. 2018;13(12):e0207229. doi:10.1371/ journal.pone.0207229 
41. Gube A, Gonfa R, Tadesse T. Evaluation of antibiotic use in medical ward of Fitche District hospital, north Showa zone, Oromia region, Ethiopia. Adv Pharmacoepidemiol Drug Saf. 2017;6(217):2167.

42. Gashaw T, Sisay M, Mengistu G, Amare F. Investigation of prescribing behavior at outpatient settings of governmental hospitals in eastern Ethiopia: an overall evaluation beyond World Health Organization core prescribing indicators. J Pharm Policy Pract. 2018;11:26. doi:10.1186/s40545-018-0152-Z

43. Yohannes Y, Mengesha Y, Tewelde Y. Timing, choice and duration of perioperative prophylactic antibiotic use in surgery: a teaching hospital based experience from Eritrea, in 2009. J Eritrean Med Assoc. 2009;4(1):65-67.

44. Wambale J, Iyamba J, Mathe D, Kavuo S. Takaisi-kikuni point prevalence study of antibiotic use in hospitals in Butembo. Int J Med Sci. 2016.

45. Landstedt K, Sharma A, Johansson F, Lundborg CS, Sharma M. Antibiotic prescriptions for inpatients having non-bacterial diagnosis at medicine departments of two private sector hospitals in Madhya Pradesh, India: a cross-sectional study. BMJ Open. 2017;7(4): e012974. doi:10.1136/bmjopen-2016-012974

46. Getachew E, Aragaw S, Adissie W, Agalu A. Antibiotic prescribing pattern in a referral hospital in Ethiopia. Afr $J$ Pharm Pharmacol. 2013;7(38):2657-2661. doi:10.5897/AJPP12.505

47. Admassie E, Begashaw B, Hailu W. Assessment of drug use practices and completeness of prescriptions in Gondar University Teaching Referral Hospital. Int J Pharm Sci Res. 2013;4(1):265.

48. Chem ED, Anong DN, Akoachere J-FKT, Godman B. Prescribing patterns and associated factors of antibiotic prescription in primary health care facilities of Kumbo East and Kumbo West Health Districts, North West Cameroon. PLoS One. 2018;13(3):e0193353. doi:10.1371/journal.pone.0193353

49. El Mahalli AA, Akl OA, Al-Dawood SF, et al. WHO/INRUD patient care and facility-specific drug use indicators at primary health care centres in Eastern province, Saudi Arabia. East Mediterr Health J. 2012;18(11):1086-1090. doi:10.26719/2012.18.11.1086

50. Gutema G, Håkonsen H, Engidawork E, Toverud E-L. Multiple challenges of antibiotic use in a large hospital in Ethiopia-a wardspecific study showing high rates of hospital-acquired infections and ineffective prophylaxis. BMC Health Serv Res. 2018;18(1):326. doi:10.1186/s12913-018-3107-9

51. Ntšekhe M, Hoohlo-Khotle N, Tlali M, Tjipura D. Antibiotic prescribing patterns at six hospitals in Lesotho Published for the U.S. Agency for International Development by the Strengthening Pharmaceutical Systems Program. Arlington: Management Sciences for Health; 2011. In: Accessed on April 2, 2020, from https://www. msh.org/sites/msh.org/files/siapstechbrief-services-antimicrobial-stew ardship-17july2014_0.pdf.

52. Aravamuthan A, Arputhavanan M, Subramaniam K, Udaya Chander J SJ. Assessment of current prescribing practices using World Health Organization core drug use and complementary indicators in selected rural community pharmacies in Southern India. $J$ Pharm Policy Pract. 2017;10(1):1. doi:10.1186/s40545-016-0074-6
53. Shankar RP, Partha P, Shenoy NK, Easow JM, Brahmadathan KN. Prescribing patterns of antibiotics and sensitivity patterns of common microorganisms in the internal medicine ward of a teaching hospital in Western Nepal: a prospective study. Ann Clin Microbiol Antimicrob. 2003;2(1):7. doi:10.1186/1476-0711-2-7

54. WHO. How to Investigate drug use in health facilities: selected drug use indicators - EDM research series no. 0071993 Available from: https:/www.who.int/medicines/publications/how-to-investigate_drug -use/en/. Accessed July 23, 2020.

55. Kallen MC, Prins JM. A systematic review of quality indicators for appropriate antibiotic use in hospitalized adult patients. Infect Dis Rep. 2017;9(1). doi:10.4081/idr.2017.6821

56. Tanaka A, Yano A, Watanabe S, Tanaka M, Araki H. Impact of switching from intravenous to oral linezolid therapy in Japanese patients: a retrospective cohort study. J Pharm Policy Pract. 2016;9 (1):35. doi:10.1186/s40545-016-0087-1

57. Gidebo KD, Summoro TS, Kanche ZZ, Woticha EW. Assessment of drug use patterns in terms of the WHO patient-care and facility indicators at four hospitals in Southern Ethiopia: a cross-sectional study. BMC Health Serv Res. 2016;16(1):643. doi:10.1186/s12913016-1882-8

58. Ahmed AM, Awad AI. Drug use practices at pediatric hospitals of Khartoum State, Sudan. Ann Pharmacother. 2010;44(12):1986-1993. doi:10.1345/aph.1P423

59. Mudenda W, Chikatula E, Chambula E, et al. Prescribing patterns and medicine use at the university teaching hospital, Lusaka, Zambia. Med J Zambia. 2016;43(2):94-102.

60. Sisay M, Mengistu G, Molla B, Amare F, Gabriel T. Evaluation of rational drug use based on World Health Organization core drug use indicators in selected public hospitals of eastern Ethiopia: a cross sectional study. BMC Health Serv Res. 2017;17(1):161. doi:10.1186/ s12913-017-2097-3

61. Veronin MA. Should we have concerns with generic versus brand antimicrobial drugs? A review of issues. J Pharm Health Serv Res. 2011;2(3):135-150. doi:10.1111/j.1759-8893.2011.00059.x

62. Fadare JO, Adeoti AO, Desalu OO, et al. The prescribing of generic medicines in Nigeria: knowledge, perceptions and attitudes of physicians. Expert Rev Pharmacoecon Outcomes Res. 2016;16 (5):639-650. doi:10.1586/14737167.2016.1120673

63. Al Shimemeri A, Al Ghadeer H, Memish Z. Antibiotic utilization pattern in a general medical ward of a tertiary medical center in Saudi Arabia. Avicenna J Med. 2011;1(1):8. doi:10.4103/2231-0770.83717
Infection and Drug Resistance

\section{Publish your work in this journal}

Infection and Drug Resistance is an international, peer-reviewed openaccess journal that focuses on the optimal treatment of infection (bacterial, fungal and viral) and the development and institution of preventive strategies to minimize the development and spread of resistance. The journal is specifically concerned with the epidemiology of antibiotic resistance and the mechanisms of resistance development and diffusion in both hospitals and the community. The manuscript management system is completely online and includes a very quick and fair peerreview system, which is all easy to use. Visit http://www.dovepress.com/ testimonials.php to read real quotes from published authors. 